\title{
DERECHOEIECTORAL
}

\section{Aportes de la jurisprudencia electoral a los Objetivos de Desarrollo Sostenible en el período 2015-2020}

Max Alberto Esquivel Faerron*

https://doi.org/10.35242/RDE $202132 \quad 2$

\section{Nota del Consejo Editorial}

Recepción: 11 de junio de 2021.

Revisión, corrección y aprobación: 5 de julio de 2021.

Resumen: El artículo analiza la forma en la que el trabajo desarrollado por el Tribunal Supremo de Elecciones, en su función jurisdiccional, ha colaborado de manera decisiva a que el país cumpla los compromisos adquiridos en la Agenda 2030 de la Organización de la Naciones Unidas y en los Objetivos de Desarrollo Sostenible, lo cual, a su vez, ha contribuido a enfrentar con fortaleza institucional los retos que plantea la actual coyuntura para la democracia costarricense.

Palabras clave: Función jurisdiccional / Jurisdicción electoral / Resoluciones electorales / Fortalecimiento de la democracia / Principio de igualdad / Paridad política / Estado de derecho / Convenios internacionales / Desarrollo sostenible / Tribunal Supremo de Elecciones / Organización de la Naciones Unidas.

Abstract: The article analyzes the way in which the work done by the Supreme Electoral Tribunal, in its jurisdictional function, has decisively contributed to the country's achievement of the commitments acquired by the 2030 Agenda of the Organization of American States and the Sustainable Development Objectives. This in turn, has contributed to facing, with institutional strength, the challenges brought about by the current Costa Rican democratic juncture.

Key Words: Jurisdictional function / Electoral jurisdiction / Electoral resolutions / Strengthening of democracy / Equality principle / Political parity / State of Law / International Treaties / Sustainable development / Supreme Electoral Tribunal / Organization of American States.

\footnotetext{
* Costarricense, abogado y politólogo, correo mesquivel@tse.go.cr. Licenciado en Derecho y en Ciencias Políticas por la Universidad de Costa Rica, con especialidad en Derecho Público. De 1999 a 2005 se desempeñó como defensor adjunto de los habitantes. De 2005 a 2007 fue magistrado suplente de la Sala Constitucional, y desde 2007 es magistrado propietario del Tribunal Supremo de Elecciones. En 2006 laboró como subdirector de la Escuela de Ciencias Políticas de la Universidad de Costa Rica, donde ha sido profesor de los cursos de Democracia y Derechos Humanos, Aspectos Políticos del Derecho Constitucional y Aspectos Políticos del Derecho Administrativo.
} 


\section{DERECHOELECTORAL}

\section{A MODO DE INTRODUCCIÓN}

En el año 2015 la Organización de Naciones Unidas (ONU) identificó lo que, en criterio de los países que la integran, se definieron como las prioridades que debía seguir la humanidad para alcanzar el objetivo global de un desarrollo sostenible en la Agenda $2030^{1}$.

Sobre el particular, autores como Barrero-Barrero y Barquero-Valdés señalan que los Objetivos de Desarrollo Sostenible (ODS) acordados en esa resolución de la ONU:

...se constituyen en un apoyo para cada país en su senda hacia un desarrollo sostenido, inclusivo y en armonía con el medio ambiente, a través de políticas públicas e instrumentos de presupuesto, monitoreo y evaluación. Es así como la Agenda 2030 se considera un documento social, que pone la dignidad y la igualdad de las personas en el centro. Al ser ambiciosa y visionaria, requiere de la participación de todos los sectores de la sociedad y del Estado para su implementación. (2020, p. 129).

En el ámbito de las funciones que la Constitución Política le asigna al Tribunal Supremo de Elecciones, el documento elaborado por esa organización internacional definió como objetivos y metas prioritarios de desarrollo los siguientes:

1 El siguiente texto explica los antecedentes de la resolución de Naciones Unidas sobre el particular: Hace 17 años, por iniciativa de los Estados Miembros de las Naciones Unidas, se establecieron ocho Objetivos del Desarrollo del Milenio que debieron cumplirse hasta el año 2015 (ODM) ${ }^{2}$. Sin duda alguna esta iniciativa constituyó el principio y la base de la construcción de un mundo mejor, donde los Estados focalizaron su atención en aquellos problemas que en aquel entonces consideraron prioritarios como la lucha contra la extrema pobreza, el acceso universal a la educación primaria, promover la igualdad de género y el empoderamiento de la mujer, reducir la mortalidad de los niños menores de cinco años, mejorar la salud materna, combatir el VIH/SIDA, el paludismo y otras enfermedades, garantizar las sostenibilidad del medio ambiente, y fomentar una alianza mundial para el desarrollo. No obstante a los buenos deseos y al trabajo realizado durante los quince años, llegado el 2015, lamentablemente aquellos problemas enraizados, como la pobreza extrema, en muchas sociedades no han sido resueltos y muchas personas en el mundo la siguen padeciendo. Lo mismo sucede con los otros objetivos que si bien se ha avanzado, pero no lo suficiente como para dar por resuelto dichas carencias.

Concluida esta etapa los Estados asumen nuevamente el reto de seguir trabajando por conseguir un mundo mejor. En este contexto en Nueva York, el 25 de septiembre de 2015, hace exactamente dos años, la Asamblea General de las Naciones Unidas aprobó la Agenda 2030 para el Desarrollo Sostenible. Esta está compuesta por diecisiete objetivos conocidos como los Objetivos del Desarrollo Sostenible (ODS) y por ciento sesenta y nueve metas. Se trata de un proyecto más ambicioso frente a los ODM, que incluye más del doble de propósitos. Es una nueva hoja de ruta que los Estados asumen, en el que incorporan nuevos propósitos ausentes en los ODM. (Quispe, 2018, pp. 236-237). 


\section{DERECHO EIECTORAL}

OBJETIVO 5.- Igualdad de género: Si bien es cierto que las mujeres han logrado importantes avances en la toma de cargos políticos en todo el mundo, su representación en los parlamentos nacionales de $23,7 \%$ aún está lejos de la paridad. En 46 países, las mujeres ahora ocupan más del $30 \%$ de los escaños en el parlamento nacional en al menos una cámara.

5.1.- Poner fin a todas las formas de discriminación contra todas las mujeres y las niñas en todo el mundo.

5.5.- Asegurar la participación plena y efectiva de las mujeres y la igualdad de oportunidades de liderazgo a todos los niveles decisorios en la vida política, económica y pública.

5.c.- Aprobar y fortalecer políticas acertadas y leyes aplicables para promover la igualdad de género y el empoderamiento de todas las mujeres y las niñas a todos los niveles.

OBJETIVO 10.- Reducción de las desigualdades:

10.2.- De aquí a 2030, potenciar y promover la inclusión social, económica y política de todas las personas, independientemente de su edad, sexo, discapacidad, raza, etnia, origen, religión o situación económica u otra condición.

10.3.- Garantizar la igualdad de oportunidades y reducir la desigualdad de resultados, incluso eliminando las leyes, políticas y prácticas discriminatorias y promoviendo legislaciones, políticas y medidas adecuadas a ese respecto.

OBJETIVO 16.- Paz, Justicia e Instituciones Sólidas: (El estado de derecho y el desarrollo tienen una interrelación significativa y se refuerzan mutuamente, por lo que es esencial para el desarrollo sostenible a nivel nacional e internacional).

16.3.- Promover el estado de derecho en los planos nacional e internacional y garantizar la igualdad de acceso a la justicia para todos.

16.6.- Crear a todos los niveles instituciones eficaces y transparentes que rindan cuentas.

16.7.- Garantizar la adopción en todos los niveles de decisiones inclusivas, participativas y representativas que respondan a las necesidades.

16.9.- De aquí a 2030, proporcionar acceso a una identidad jurídica para todos, en particular mediante el registro de nacimientos. 


\section{DERECHOELECTORAL}

16.10.- Garantizar el acceso público a la información y proteger las libertades fundamentales, de conformidad con las leyes nacionales y los acuerdos internacionales. (ONU, 2020).

Cabe indicar, por su parte, que, a la luz de los objetivos establecidos en esta declaración, autores como Freidenberg y Saavedra han identificado algunas vías de acción para enfrentar la crisis que sufren los sistemas político-electorales en América Latina:

... las democracias latinoamericanas enfrentan retos importantes respecto a su supervivencia sin dejar de hacer bien lo que ya saben hacer: elecciones competitivas, justas y plurales de manera ininterrumpida. Estos retos tienen que ver con la capacidad de inclusión e igualdad de todos los que participan en ella; con la vigencia del Estado de derecho y el desarrollo de capacidades estatales, a partir de poder cumplir con las funciones básicas que se espera que haga el Estado; con la posibilidad de canalizar el descontento social y de que las elecciones y las instituciones sean capaces de procesar dicha conflictividad. (2020, p. 35).

De lo dicho por Freidenberg y Saavedra y lo establecido por la ONU al definir los Objetivos de Desarrollo Sostenible, quedan claramente definidos dos ámbitos de acción para el trabajo que, en esa coyuntura, se constituye en hoja de ruta para el órgano constitucional encargado de organizar, dirigir y vigilar todo lo relativo al sufragio en nuestro país. Me refiero al aumento en la capacidad de inclusión e igualdad política de la ciudadanía en la dinámica político-electoral, así como al fortalecimiento de las metodologías e institutos del Estado democrático de derecho asociadas a los procesos electorales.

El objetivo del presente artículo es mostrar la forma en la que el trabajo desarrollado por el Tribunal Supremo de Elecciones, en su función jurisdiccional, ha colaborado de manera decisiva a que el país cumpla los compromisos adquiridos en la Agenda 2030 y en los ODS lo cual, a su vez, ha contribuido a enfrentar con fortaleza institucional los retos que plantea la actual coyuntura para la democracia costarricense.

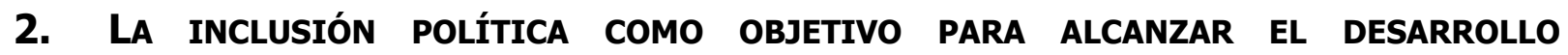 SOSTENIBLE}

Al plantearse como objetivo de desarrollo sostenible n. 5 "Lograr la igualdad entre los géneros y empoderar a todas las mujeres y las niñas", la ONU tuvo como punto de partida que, en el campo político: "...las leyes y las normas sociales discriminatorias continúan siendo generalizadas, las mujeres siguen estando infrarrepresentadas a 


\section{DERECHOELECTORAL}

todos los niveles de liderazgo político" (ONU, 2020). Ello se evidencia en la representación de las mujeres en los parlamentos nacionales en todo el mundo que es de $23,7 \%$, aunque aquí en Costa Rica ya alcanzó la cifra de $45,6 \%$ en virtud de reformas que establecieron la paridad con alternancia en la normativa electoral y decisiones del propio TSE que profundizaron la efectiva aplicación de tales medidas.

Decisiones inclusivas similares se requieren, también, en relación con otros segmentos de la población que aquejan serias desigualdades en diversos ámbitos de la vida social en virtud de criterios como su edad, sexo, discapacidad, raza, etnia, origen, religión, situación económica u otra condición.

Por su parte, según el especialista Fernández Rodríguez, el mandato de la resolución de Naciones Unidas que establece los ODS relacionados con la creación de instituciones eficaces, responsables e inclusivas "en todos los niveles" implica lo siguiente:

La inclusión va más allá de la confianza ciudadana en las instituciones y el sometimiento de estas al principio de legalidad, a la jerarquía normativa, a la responsabilidad y a la interdicción de la arbitrariedad (a los que alude, por ejemplo, el art. 9.3 de la constitución española). Hace referencia a un plus de exigencia ética anclada en el Estado Social y en la igualdad material y equidad que lo caracteriza. La inclusión determina un compromiso con las personas para que no queden sin oportunidades ni sean, obviamente, discriminadas. Incluir es también remover obstáculos que impiden la igualdad y la participación (como dicen los art. 3 párrafo 2 de la constitución italiana y 9.2 de la española), y aportar apoyos que faciliten la integración de las personas necesitadas de especial protección, su autonomía e independencia. (2018, p. 12).

En esa misma dirección y citando a Alberto Binder, resulta impensable una democracia cuyo principal problema no sea revertir las condiciones de desigualdad que afectan a importantes grupos poblacionales (2001, p. 6).

En el campo de la política electoral esta tarea debe enfocarse en la promoción del principio de igualdad política, según el cual todas las personas ciudadanas son políticamente iguales y, como tales, deben tener una participación efectiva, informada e igualitaria en la toma de decisiones, lo cual garantiza su intervención en el control final de la agenda política.

Es decir, resulta indispensable que la institucionalidad electoral incorpore medidas que garanticen, hasta el extremo, la vigencia de este atributo ciudadano -la igualdad 


\section{DERECHOEIECTORAL}

política- y la consecuente construcción de un sistema político inclusivo. Y es que debe reconocerse que:

... debido a la desigualdad en recursos sociales, algunos ciudadanos obtienen una influencia significativamente mayor que otros sobre las decisiones, políticas y las acciones del gobierno. Estas asimetrías no son, por desgracia, triviales. El resultado es que los ciudadanos no son iguales políticamente -ni mucho menos- y así, la fundamentación moral de la democracia, la igualdad política de los ciudadanos, se ve seriamente vulnerada. (Dahl, 1999, p. 36).

Desde ese punto de vista, la inclusión en el sistema electoral debe garantizarse en situaciones tan diversas como el ejercicio del sufragio activo y pasivo, las oportunidades de participación política en condiciones de equidad, la democracia interna de los partidos y la equidad en la contienda.

Al contribuir a alcanzar tan importantes metas, se logra cimentar la capacidad de inclusión política que se requiere para enfrentar, con medidas institucionales, las amenazas que se ciernen sobre la democracia.

\section{El FORTALECIMIENTO DEL ESTADO DEMOCRÁtiCO DE DERECHO COMO OBJETIVO PARA ALCANZAR EL DESARROLLO SOSTENIBLE}

Ya habíamos mencionado que el objetivo de desarrollo sostenible número 16 definido por la ONU busca: "Promover sociedades pacíficas e inclusivas para el desarrollo sostenible, facilitar el acceso a la justicia para todos y crear instituciones eficaces, responsables e inclusivas a todos los niveles" (ONU, 2020).

Para identificar los ámbitos en los que tal disposición resulta aplicable al quehacer de este organismo electoral, conviene desglosar su contenido con la ayuda del estudio que sobre el particular realizó el tratadista Fernández Rodríguez. El autor comienza por explicar que el sentido amplio del concepto 'paz', como se plantea en la resolución, se refiere a:

la vocación de afrontar todas las formas de violencia y de promocionar sociedades inclusivas, las cuales exigen vías de participación ciudadana. Sólo una ciudadanía con derechos y garantías, lo que dará igualdad de oportunidades, puede conformar comunidades estables y pacíficas $y$, por ende, generar un desarrollo sostenible. (Fernández, , p. 10). 


\section{DERECHO ELECTORAL}

Por su parte, respecto de la justicia, la resolución hace clara referencia al acceso a esta como un derecho subjetivo que permite resolver las pretensiones que sean planteadas por la ciudadanía ante las instancias previstas por el ordenamiento jurídico para la atención de dichas demandas o la resolución de conflictos. Asimismo, en cuanto a la referencia a instituciones sólidas y estables, la resolución: "se refiere a la posibilidad de una gobernabilidad efectiva, en conexión con la idea de buen gobierno. Es decir, que la arquitectura de los órganos públicos dé seguridad jurídica, confianza a la ciudadanía y estabilidad al sistema" (Fernández, 2018, p. 11).

Constituye, en ese sentido, una referencia directa a la vigencia del Estado de derecho y a los principios constitucionales que lo integran, a saber, el principio de legalidad, el principio de tutela judicial efectiva, el principio de rendición de cuentas y el principio de garantía patrimonial (Santamaría, 1987).

Si se realiza un esfuerzo de concreción institucional para determinar las áreas en las que el TSE puede contribuir desde el ejercicio de sus competencias para alcanzar tales cometidos en materia político electoral, pueden identificarse diversos ámbitos de acción tan importantes como el acceso a la justicia electoral y a una identidad jurídica fiable, las reglas claras y estables en la contienda electoral, la transparencia y la rendición de cuentas en el manejo del financiamiento partidario, las limitaciones al derecho de participación que aseguran la imparcialidad en el ejercicio de la función pública y el acceso público a la información en sus diferentes vertientes.

Como se verá, con sus aportes jurisdiccionales el TSE parte del concepto de que el libre ejercicio de los derechos político político-electorales, así como la abierta y equitativa disputa por el ejercicio del poder, requieren de institutos y metodologías propios del Estado democrático de derecho que sean seguros, estables, efectivos y transparentes; ingredientes necesarios para resguardar la democracia frente los desafíos que plantea la dinámica actual del sistema político costarricense.

\section{APORTES DESDE LA FUNCIÓN JURISDICCIONAL EN EL PERÍODO 2015-2020}

Para abordar los aportes realizados por el TSE desde el punto de vista jurisdiccional en el período 2015-2020, se clasificaron las sentencias más relevantes del período 20152021 en dos ejes de análisis, a saber: 1) las vinculadas a decisiones inclusivas que lograron fortalecer el principio de igualdad política y 2) aquellas orientadas a fortalecer el Estado democrático de derecho según el contenido indicado en el párrafo anterior, 


\section{DERECHOELECTORAL}

temas que resultan contestes con varios de los Objetivos de Desarrollo Sostenible, según se explicó al inicio de este artículo².

\subsection{EN RELACIÓN CON EL PRINCIPIO DE IGUALDAD POLÍTICA}

A través del ejercicio de su función jurisdiccional, el Tribunal Supremo de Elecciones ha realizado contribuciones importantes para asegurar que el ejercicio de los derechos político-electorales, así como los procesos diseñados para la escogencia de autoridades internas partidarias y/o para la designación de los cargos de elección popular, cumplan con el mandato de ser ampliamente participativos, democráticos e inclusivos.

Como se verá, tal desarrollo jurisprudencial ha permitido la adopción de decisiones inclusivas en temas tan relevantes como el ejercicio del sufragio activo en los procesos electorales, en los procesos internos de las agrupaciones políticas y en los procesos de referéndum. También se agruparon las resoluciones vinculadas con la inclusión en el ejercicio del sufragio pasivo en las candidaturas para diputaciones de la Asamblea Legislativa, en las candidaturas para cargos de elección municipales y en los procesos de renovación de estructuras. Adicionalmente, se trabajó con fallos que desarrollaron la inclusión en la tutela del derecho al ejercicio efectivo del cargo, primero en el ámbito de la relación entre la alcaldía y la primera vicealcaldía y luego en el ámbito de los concejos municipales. Finalmente se aglutinaron las resoluciones que plantearon la inclusión en el ejercicio del derecho de asociación con fines políticos a través de la creación de partidos políticos.

A continuación, se sintetizan las resoluciones más importantes dictadas por el TSE en este ámbito durante el período que se analiza:

- Se reconocieron medidas de protección especial para grupos en condición de vulnerabilidad que, dada su situación, podrían ver amenazado el libre ejercicio del sufragio y el respeto a la voluntad expresada en las urnas. (Voto 1347-E4-2016).

- Se adoptaron acciones para asegurar que el voto asistido, utilizado para facilitar el ejercicio del sufragio de las personas adultas mayores o que posean alguna condición especial, no se constituyera en una condicionante contra la libre determinación de cada votante. (Voto 1408-E4-2020).

\footnotetext{
${ }^{2}$ La siguiente síntesis toma como base la revisión jurisprudencial realizada por el autor de este artículo para la elaboración del Informe de gestión presentado ante la Corte Suprema de Justicia con ocasión de su reelección como magistrado propietario del TSE para el período 2021-2027.
} 


\section{DERECHO ELECTORAL}

- Se ordenó a la Caja Costarricense de Seguro Social (CCSS) facilitar el traslado a los recintos de votación- de los ciudadanos internados en los centros hospitalarios para personas con enfermedades mentales, siempre y cuando lo permitiese el criterio médico. Posteriormente, a partir del proceso electoral municipal de 2016, se previó la instalación de juntas receptoras de votos en hospitales psiquiátricos, para garantizar el ejercicio del voto de sus pacientes. (Voto 53-E1-2018).

- Se ordenó detener la publicación en medios de comunicación de manifiestos que, por medio de la invocación o apelación a motivos exclusivamente religiosos, pretendían incidir en la voluntad del elector a favor o en contra de alguna de las opciones en contienda. (Voto 1062-E3-2016).

- Se tuteló el derecho de las diversas iglesias o credos religiosos de tomar posición sobre los problemas sociales del país, explicitar su postura frente a temas puntuales de la realidad nacional, manifestar públicamente el marco axiológico de su credo religioso particular, predicar la fe con auténtica libertad, enseñar su doctrina social, ejercer su misión terrenal sin traba alguna y dar juicio moral, incluso, en materias referentes al orden público. (Voto 1375-E1-2018).

- Se dispuso que dentro del local de votación solo los agentes electorales pueden utilizar dispositivos de comunicación, siempre y cuando su empleo no ponga en riesgo la garantía del carácter secreto del sufragio y no altere o perturbe el transcurso normal de la actividad comicial. También quedó absolutamente prohibido su empleo dentro del recinto de votación. (Voto 578-E8-2018)

- Se aclaró que no existe obligación de los candidatos de los partidos políticos de participar en debates o actividades similares, en tanto esto es parte de la toma de decisiones en el marco de su estrategia política. Tampoco tienen los partidos obligación de contar con un documento de propuestas programáticas que deban presentar como requisito para poder participar en la elección. Ambos mecanismos son parte de las decisiones que adoptan las agrupaciones en el marco de su estrategia política y, en ese tanto, parte de los insumos para la decisión final del electorado. (Voto 1667-E1-2018).

- Se estableció que la participación de una persona designada para integrar alguno de los órganos del partido resulta ser un acto de naturaleza intransferible que solo puede asumir esa misma persona, lo que excluye cualquier forma de delegación. (Voto 4199-E8-2015).

- Se estableció que, para que una asamblea nacional pueda llevarse a cabo en un ambiente de irrestricta libertad política, deberá sesionar en un inmueble que, por 


\section{DERECHO ELECTORAL}

su naturaleza, resulte ajeno a cualquier influencia externa que pueda incidir en la voluntad de sus delegados. (Voto 3484-E1-2015 y Voto 7418-E1-2016).

- Se ordenó a los partidos que cualquier proceso de afiliación que se lleve a cabo deberá contar con reglas claras desde el inicio y con una prohibición absoluta de modificación a fin de dotarlo de seguridad jurídica. (Voto 3075E2-2017).

- Se aclaró que el estado de morosidad con las cuotas partidarias no es motivo suficiente para tener por suspendida la militancia partidaria sin que, previamente, se hubiera hecho un requerimiento válido de pago. (Voto 4580-E1-2017).

- Se interpretó que la normativa electoral vigente no permite la doble militancia en diversas agrupaciones políticas y que, por ello, la intervención de un militante en otro partido político -a través de actos que reflejen de manera inequívoca su decisión de desligarse de la agrupación política por afiliarse a otra- supone la renuncia tácita e inmediata de la militancia ejercida en el anterior partido político. (Voto 2873-E1-2019).

- Se aclaró que las y los ciudadanos pensionados por el régimen de invalidez no tienen limitación para postular su nombre a un cargo de elección popular ni para asumir su eventual ejercicio. (Voto 4089-E8-2015).

- Se detalló que la prohibición temporal de reingreso a puestos de la Administración pública (centralizada o descentralizada) y a las empresas públicas, contenida en el artículo 27 de la Ley para el Equilibrio Financiero del Sector Público, para quienes se acojan al beneficio de la movilidad laboral, no puede tenerse como un requisito de elegibilidad que impida la postulación y el ejercicio de cargos de elección popular. (Voto 2577-E8-2016).

- Se estableció que no cabe que una administración pública traslade laboralmente a un trabajador a otra zona del país si este es, a su vez, candidato a un cargo municipal de elección popular y el cambio de domicilio implica la pérdida del requisito de residencia efectiva que debe cumplir desde su postulación para aspirar a esa posición. (Voto 7156-E1-2015).

- Por unanimidad se instruyó a las agrupaciones políticas que la paridad en las listas de candidaturas a los puestos "plurinominales" obliga a los partidos a integrar cada una de esas nóminas con un 50 \% de cada sexo, colocados en forma alterna (paridad vertical con alternancia) y que esa proporción debe respetarse, también, en los encabezamientos de las listas pertenecientes a una misma circunscripción territorial (paridad horizontal). Se estableció que la citada regla no resulta aplicable a las candidaturas presentadas por agrupaciones cantonales para regidurías propietarias y suplentes, a las listas postuladas por 


\section{DERECHO ELECTORAL}

coaliciones y a las nóminas para las concejalías municipales de distrito únicas en su cantón. Corresponde a los partidos definir, en su normativa interna, los mecanismos para dar cumplimiento a este régimen paritario. (Voto 1724-E82019).

- Por mayoría se precisó que el derecho fundamental a la reelección, la particularidad misma de los puestos y la necesidad de asegurar el contenido esencial del derecho de participación política a todos los habitantes de los gobiernos locales tornan imposible la aplicación de la paridad horizontal en los puestos "uninominales" (alcaldías, sindicaturas e intendencias, así como sus respectivas suplencias); de modo tal que, en esos casos, el derecho de participación igualitaria se satisface con la alternancia dentro de cada nómina (vertical). (Voto 1724-E8-2019).

- Se advirtió que los tribunales de ética y disciplina (TED) de los partidos no pueden suspender cautelarmente la militancia de uno de sus partidarios fundamentados únicamente en la existencia de un procedimiento disciplinario interno que podría derivar en su expulsión del partido. (Voto 4989-E1-2015).

- Se determinó que el comité ejecutivo superior (CES) de un partido no puede arrogarse la autoridad de aplicar a uno de sus candidatos una acción correctiva asumiendo competencias que son propias de los órganos encargados de juzgar la ética y la disciplina internas. (Voto 718-E1-2020).

- Se precisó que, una vez designados válidamente los candidatos a cargos de elección popular, estos no pueden ser sustituidos, sino por causas justificadas o por renuncia voluntaria. (Voto 6269-E1-2017).

- Se estableció que es válida la exigencia de que cada precandidato de una agrupación presente un número determinado de adhesiones para su inscripción siempre que este no resulte irrazonable ni desproporcionado. (Voto 6959-E12016).

- Se advirtió que los ajustes compensatorios de paridad que le corresponda realizar al tribunal electoral interno (TEI) de un partido deben hacerse antes de las declaratorias de elección y nunca posteriormente. (Voto 2605-E2-2019).

- Se reiteró que ningún partido político puede dejar sin efecto la designación de un militante que haya sido escogido para un cargo de la estructura interna sin concederle al menos una audiencia previa que permita resguardar el debido proceso. Además, se adicionó que lo establecido respecto de la necesidad de respetar el debido proceso resulta también aplicable en aquellos casos en que los militantes enfrenten procesos dentro del partido que pueden conllevar una afectación a sus derechos de carácter político-electoral. (Votos 3106-E1-2017, 5255-E1-2017 y 6253-E1-2017). 


\section{DERECHO ELECTORAL}

- Se reconoce el derecho de los militantes de un partido a exigir al comité ejecutivo superior la debida diligencia para evitar que la convocatoria tardía de las asambleas partidarias ponga en riesgo el proceso de renovación de estructuras y su eventual participación en los procesos electorales. (Votos 3462-E1-2017, 3463-E1-2017, 3464-E1-2017 y 3570-E1-2017).

- Se indicó que la autorización del uso de instalaciones educativas para llevar a cabo procesos políticos inherentes a la organización interna de dos agrupaciones políticas debe darse en condiciones de igualdad para todos los partidos, por lo que un trato dispar o una denegatoria sin un sustento riguroso constituiría una arbitrariedad incompatible con el derecho de la Constitución. (Voto 3558-E1-2017).

- Se precisó que los órganos partidarios no pueden obligar a sus militantes a permanecer contra su voluntad ocupando un puesto dentro de la estructura interna del partido; $y$, además, que resulta contrario a los derechos políticoelectorales de estos que su agrupación política les limite o impida su participación como candidatos a puestos dentro de la estructura partidaria, para los cuales reúnen los requisitos legales y estatuarios. Asimismo, se estableció que los correligionarios gozan de absoluta libertad para renunciar a los puestos en que fueron designados dentro de la estructura interna de un partido político cuando así lo deseen, sin importar el motivo que fundamenta su decisión. (Voto 8541-E8-2018).

- Se advirtió que el miembro suplente designado en un cargo dentro de la estructura interna del partido está facultado, de pleno derecho, para asumir el puesto de su titular con motivo de su renuncia, hasta tanto el partido, de acuerdo con sus procedimientos internos, realice el nombramiento correspondiente. (Voto 8541-E8-2018).

- Se previno que la alcaldía de un gobierno local tiene la obligación de dotar a las vicealcaldías de recursos humanos y materiales idóneos para el desempeño de sus tareas como lo son, por ejemplo, un espacio físico adecuado, suministros de oficina y equipo informático, entre otros. (Voto 4834-E1-2017).

- Se aclaró que todo interesado en postularse a una primera vicealcaldía debe cumplir con los requisitos que el ordenamiento jurídico prevé para el puesto de alcalde, lo cual incluye, entre otros, el estar inscrito electoralmente, por lo menos con dos años de anterioridad, en el cantón donde ha de servir el cargo. (Voto 5834-E8-2019).

- Se insistió en que el cargo de primer vicealcalde no es accesorio o irrelevante dentro del engranaje ejecutivo de la municipalidad. Por el contrario, su papel es absolutamente central en ese ámbito, a tal punto que, dentro del esquema 


\section{DERECHO ELECTORAL}

organizativo de los gobiernos locales, está solo por debajo de la persona que ostenta la alcaldía. (Voto 7270-E1-2017).

- Se reiteró que el alcalde municipal puede válidamente definir y, eventualmente, reconfigurar las tareas asignadas a la persona que ocupe la vicealcaldía municipal. Lo que está vedado es que no le asigne funciones del todo o que, asignándolas, las tareas encomendadas no se correspondan con el cargo. (Voto 4933-E1-2019).

- Se aclaró que entre el alcalde y los regidores no hay relación de subordinación y que el presidente municipal no puede limitar derechos, solo ordenar el uso de la palabra y definir el orden de la agenda. (Voto 2190-E1-2019).

- Se especificó que la potestad disciplinaria de los partidos políticos debe ser ejercida con respeto a los derechos fundamentales del investigado, cumpliendo las garantías mínimas del debido proceso, que abarcan, entre otros: el traslado de cargos al afectado, el acceso al expediente, un plazo razonable para la preparación de su defensa, audiencia y oportunidad de aportar prueba para respaldarla, la debida fundamentación de las resoluciones que pongan fin al procedimiento y el derecho a recurrir la resolución sancionatoria. (Voto 7115E1-2016).

- Se determinó que la información sobre la militancia en una agrupación política es de índole personal, por lo que ningún ciudadano está comprometido a hacerla pública. Al calificar tal información como dato sensible, se estableció que sólo puede ser suministrada a órganos que realizan función jurisdiccional y también a instancias administrativas si lo autoriza expresamente el titular del dato. (Voto 2132-E8-2017).

- Se especificó que el padrón electoral interno de una agrupación política es accesible únicamente por parte de sus militantes y que el dato sobre los nombramientos de partidarios en los diversos cargos internos de representación territorial y en los órganos de la estructura partidaria sí constituye información de acceso público, pues esas designaciones están sujetas al principio de publicidad registral. Igualmente, la información de contacto de los precandidatos a diferentes cargos internos y de elección popular debe estar disponible para los afiliados; además, los contendientes deben tener acceso a conocer al electorado y delegados de la circunscripción por la que aspiran a obtener un cargo de dirección o representación, así como a un medio de contacto con ellos (como podría serlo el correo electrónico). (Votos 2074-E12017 y 2279-E1-2017).

- Se indicó que, con fundamento en el principio de libertad, un medio de comunicación privado no está obligado a invitar a todos los candidatos a sus 


\section{DERECHOELECTORAL}

debates. Sin embargo, si pretende utilizar un espacio propiedad del Estado, sí debe garantizar un trato equitativo para todas las fuerzas políticas. (Voto 7450E8-2017).

- Se autorizó la difusión de campañas publicitarias que el Instituto Nacional de las Mujeres programe antes de la convocatoria a elecciones con el fin de incentivar y propiciar la participación y el debate entre la clase política y sus posturas para promover el desarrollo humano de las mujeres, aunque luego de esa convocatoria dicha publicidad no podría difundirse en caso de contener interpelaciones directas a los partidos políticos en contienda. (Voto 4869-E8-2017).

- Se determinó que no resulta jurídicamente válido que los partidos políticos o sus candidatos divulguen mensajes con insultos soeces, o bien, que constituyan propaganda de la proscrita en el párrafo 5 del artículo 13 de la Convención Americana de Derechos Humanos, a saber, toda propaganda en favor de la guerra y toda apología del odio nacional, racial o religioso que constituyan incitaciones a la violencia o cualquier otra acción ilegal similar contra cualquier persona o grupo de personas, por ningún motivo, inclusive de raza, color, religión, idioma u origen nacional. En esos casos, las empresas propietarias de los medios estarían habilitadas, según lo estimen oportuno, para no difundir el mensaje publicitario en cuestión. También el TSE podría intervenir para evitar su divulgación. (Votos 0220-E1-2018 y 0849-E1-2018).

- Se dispuso que las personas militantes de un partido político que asuman la condición de servidores públicos y ocupen, de acuerdo con la naturaleza de su investidura o jerarquía, alguno de los cargos con prohibición absoluta de participación político-electoral contemplado en el párrafo segundo del artículo 146 del Código Electoral, no requieren renunciar a su militancia. Ello en virtud de que desde el momento en que aceptan ocupar un cargo público, tal asentimiento supone la sujeción al deber de imparcialidad político-electoral y, por ende, se entiende suspendida, de pleno derecho, su militancia. (Voto 1459E8-2015).

- Se estableció que la omisión de las autoridades encargadas de tomar juramento a funcionarios públicos, que deban cumplir ese requisito, se constituye en un obstáculo ilegítimo para el ejercicio del cargo de que se trate, especialmente si se considera que el trámite de juramentación no representa un mero formalismo -como rito previo-, sino un requisito de eficacia. (Voto 7041-E12016). 


\section{DERECHO ELECTORAL}

\subsection{EN RELACIÓn CON EL FORTALECIMIENTO DEL ESTADO DEMOCRÁTICO DE DERECHO}

Ya explicamos cómo, según los Objetivos del Desarrollo Sostenible, el fortalecimiento del Estado de derecho constituye una meta impostergable para contribuir al mejoramiento de la calidad de vida de la población a través de la construcción de sociedades pacíficas con instituciones eficaces, responsables, transparentes e inclusivas.

En el caso del ámbito político electoral, ello implica la consolidación del TSE y de las agrupaciones políticas como mecanismos institucionales en el sistema político, además de la tutela efectiva del acceso a información y datos de naturaleza pública, del derecho de petición, la transparencia y rendición de cuentas en el accionar partidario y de funcionarios públicos, un adecuado manejo del financiamiento partidario y el necesario acceso a la justicia y a la identidad jurídica por parte de los ciudadanos. Todos estos elementos permitirán un entorno favorable para la participación política activa y el ejercicio de los derechos político-electorales.

A continuación, se sintetizan las resoluciones más importantes dictadas por el TSE en este ámbito entre los años 2015 y 2020 :

- Se enfatizó en que las disposiciones que rigen una contienda electoral interna deben estar totalmente claras al momento de convocar a los postulantes a inscribir sus candidaturas, existiendo, igualmente, una prohibición absoluta para modificar esas normas en el transcurso de la contienda, pues la plena seguridad y certeza jurídica que se deben garantizar dentro de esta clase de torneos es esencial para asegurar su pureza y transparencia. Se advirtió, asimismo, que aunque sea definido por unanimidad, cualquier cambio operado con posterioridad a la convocatoria, especialmente si afecta la secretividad del voto, provoca la nulidad absoluta de la asamblea respectiva. (Voto 1431-E1-2016).

- Se instituyó que los miembros de un cuerpo colegiado, de cualquier naturaleza, tienen un derecho esencial a conocer de antemano el propósito de una determinada sesión, a fin de que puedan defender sus intereses e incluso definir si asisten o no a esta. Conforme a lo indicado, sorprender con temas no incluidos en la agenda de convocatoria, o bien, no delimitar en forma clara y precisa en la agenda los temas a tratar en una sesión es, en principio, contrario a la buena fe y, en relación con los partidos políticos, una afectación indebida al derecho de participación política. (Voto 4808-E8-2019).

- Se determinó que, en el marco de una gestión de democracia semidirecta, es jurídicamente improcedente que luego de la publicación del texto definitivo 


\section{DERECHO ELECTORAL}

de la iniciativa, este sufra modificaciones, enmiendas o correcciones. De hecho, la publicidad de los textos por someter a un proceso referendario se relaciona con el derecho que asiste a la ciudadanía de conocer, en detalle, las iniciativas que pretenden consultársele, por lo que el derecho de enmienda de los proponentes de la consulta se restringe a las etapas que anteceden a su difusión, todo ello en virtud del principio de seguridad jurídica. (Voto 3783-E9-2016).

- Se dejó establecido que ninguna propuesta para someter a referéndum la convocatoria a una Asamblea Constituyente podría habilitar la presentación de candidaturas a las diputaciones constituyentes por parte de plataformas programáticas distintas a los partidos políticos o a través de postulaciones independientes. Tampoco podrían establecerse límites a la Asamblea Constituyente excluyendo de su ámbito de acción algunos temas o disposiciones propios de la norma fundamental vigente. (Voto 6187-E9-2016).

- Se reiteró que la omisión de un concejo municipal de emitir la normativa para regular la celebración de consultas populares en su cantón, conforme al mandato expresado en el artículo 13 inciso k) del Código Municipal, vacía de contenido y torna ineficaces los mecanismos de participación ciudadana previstos en la normativa vigente, lo cual transgrede el derecho fundamental a intervenir directamente en la dirección de los asuntos de interés municipal. (Voto 6250-E1-2020).

- Se dispuso que la asamblea de mayor rango de la respectiva agrupación política es la que ratifica las candidaturas propuestas por las asambleas o los órganos consultivos cantonales. Además, está facultada para discrepar de las designaciones efectuadas por los órganos inferiores, en cuyo caso habilita a estos últimos para que formulen una nueva propuesta. Si estos órganos insisten en la postulación inicial, la asamblea de mayor rango podrá reconsiderar su postura y ratificar las candidaturas inicialmente rechazadas, o confirmar su rechazo por segunda ocasión, situación que la habilita para realizar directamente la designación, eligiendo entre las candidaturas que cumplan los requisitos exigidos por el partido y estén inscritas en el proceso electivo interno. (Votos 4418-E8-2015 y 5607-E8-2015).

- Se estableció que el retardo injustificado y excesivo en la resolución de los asuntos sometidos a los órganos internos partidarios constituye una violación del derecho de acceso a una justicia pronta y cumplida, reconocido en el artículo 41 de la Constitución Política, el cual supone el deber de la autoridad respectiva de pronunciarse con diligencia y celeridad sobre los recursos y 


\section{DERECHO ELECTORAL}

reclamos planteados por los interesados y que tal decisión fuera comunicada dentro de un plazo razonable. (Voto 3544-E1-2019).

- Se enfatizó que la imparcialidad del TED de una agrupación política constituye una garantía del debido proceso que debe asegurarse en cualquier fase del procedimiento sancionatorio, por lo que resulta improcedente que sus integrantes retomen una causa en la que se han pronunciado, por el fondo, en los casos en que su resolución final sea revocada total o parcialmente por el órgano de alzada. (Voto 2369-E8-2018).

- Se indicó que los aportes económicos que establezcan las agrupaciones políticas para la inscripción de candidaturas deben cumplir con lo siguiente: a) no deben ser irrazonables ni desproporcionados; b) deben respetar el principio de igualdad, con lo cual cada uno de los precandidatos contribuye de manera paritaria y c) el monto que se cobre debe destinarse únicamente al pago de los gastos de la respectiva convención interna. (Voto 4932-E1-2019).

- Se procedió a anular una medida cautelar dictada por un órgano interno partidario en virtud de que el tribunal de alzada, órgano encargado de resolver impugnaciones contra ese tipo de decisiones, estaba desintegrado lo cual provocaba una grosera violación a las garantías mínimas del debido proceso. (Voto 4992-E1-2015).

- Se determinó que la administración electoral podrá autorizar que se continúe con la renovación de las autoridades partidarias siempre que, al menos, se haya electo a todos los delegados propietarios distritales, cantonales o provinciales, según corresponda, aunque esté pendiente la constitución total de los órganos de ejecución. Además, se aclaró que la Dirección General del Registro Electoral y de Financiamiento de Partidos Políticos (DGRE) podrá recibir las nóminas de candidatos a cargos de elección popular, pese a que estén pendientes de nombrar algunos puestos de los diversos comités ejecutivos y fiscalías de las diversas escalas (o de otros órganos distintos de la representación territorial). Sin embargo, se reiteró la obligación del partido político de acreditar todos los nombramientos pendientes de los órganos ejecutivos o ajenos a las asambleas, y que, de no hacerlo, la agrupación no podrá percibir ningún reembolso con cargo a la contribución estatal por su participación en el ciclo electoral recién pasado (incluyendo su adelanto) o inscribir las candidaturas para las elecciones inmediatas siguientes. (Voto 5282-E3-2017).

- Se reiteró que las vacantes que se produzcan en los puestos internos del partido con motivo de la renuncia de sus miembros, posterior a la firmeza de la resolución en la que el Departamento de Registro de Partidos Políticos (DRPP) tuvo por acreditada la conclusión de una etapa dentro del proceso de 


\section{DERECHO ELECTORAL}

renovación de estructuras partidarias, no obliga al partido a tener que celebrar nuevas asambleas para llenar los cargos que han quedado sin titular o suplente, como requisito para culminar su proceso de renovación de estructuras. No obstante, se advirtió que si dentro del proceso de renovación de estructuras se suscita la afectación del quórum funcional de algún órgano, en particular por la renuncia de alguno o algunos de sus miembros, el partido deberá realizar los nombramientos de rigor como requisito para finalizar su proceso de renovación. Ello implica, de igual manera, que las vacantes que se produzcan por renuncia de los militantes en las condiciones señaladas, salvo en los casos en que se afecte el quórum funcional de un órgano u autoridad partidaria, no constituyen obstáculo para que las agrupaciones políticas culminen su proceso de renovación de estructuras y puedan percibir contribución estatal o inscribir candidaturas. (Voto 8541-E8-2018).

- Se estableció que el derecho de petición y pronta respuesta constituye una garantía electoral que asiste a los interesados para plantear requerimientos ante las agrupaciones políticas, pues asegura que estos sean atendidos en un plazo razonable, según las particularidades de cada caso, aun cuando el órgano esté desintegrado. Es decir, el interesado tiene derecho a que se le comunique el rumbo de su gestión o su resultado en un término prudencial y razonable, ya sea favorable o no a sus intereses. (Votos 6762-E1-2015, 7694-E1-2016, 857-E1-2017, 2962-E1-2017, 3401-E2-2017 у 1206-E1-2018).

- Se aclaró que el derecho de petición no resulta objeto de tutela por la vía del amparo cuando la omisión en la entrega de información se dé entre órganos de la misma administración, pues, lejos de ser una afectación a un derecho fundamental, se trata de una hipótesis de incorrecta coordinación entre dependencias. (Voto 2602-E1-2019).

- Se resolvió que la adecuada realización de las comunicaciones, siguiendo los pasos establecidos por la normativa aplicable a la materia, constituye una garantía de seguridad jurídica y respeto al debido proceso que resulta fundamental en las relaciones entre las agrupaciones políticas y sus militantes. Este proceder también debe garantizarse en el trámite de los procedimientos que lleva a cabo tanto la administración partidaria como los correspondientes a la justicia electoral. De igual manera deberá actuarse en el caso de las personas que desean activar los mecanismos para tutelar sus derechos e intereses. (Votos 6503-E1-2015, 6510-E1-2015 y 6511-E1-2015).

- Se dispuso que hay una imposibilidad legal de brindar a terceros información que, pese a estar en custodia de la administración electoral, forme parte de un proceso penal que se encuentre en la etapa preparatoria; esto incluye, por 


\section{DERECHO ELECTORAL}

supuesto, relaciones de hecho enviadas por la institución al Ministerio Público. Se señaló, además, que cuando un proceso penal -iniciado con base en información remitida por este Tribunal al Ministerio Público- se encuentra en etapa de juicio, no existe obstáculo para que se brinde a terceros la relación de hechos que -en su momento- fuera confeccionada por la administración electoral. No obstante, si el tribunal de juicio declaró privada la audiencia en algún extremo específico, la información relativa a ese punto concreto no podrá brindarse. (Voto 4333-E7-2019).

- Se precisó que la prohibición contenida en el artículo 142 del Código Electoral en relación con la difusión publicitaria de la obra realizada por algunas instituciones públicas durante las elecciones nacionales no implica silenciar al Gobierno o minar su quehacer político-institucional ni afectar o paralizar la continuidad y eficiencia de sus servicios o acciones para abordar situaciones de gran importancia dado el interés público comprometido. No obstante, tales espacios no deben contener mensajes que exalten atributos o logros de la institución, que incluyan la imagen de sus jerarcas o que produzcan la más leve sospecha de estar diseñados como estrategia política para distinguir méritos de la gestión del Gobierno en la atención de este tipo de emergencias. (Voto 6264E8-2017).

- Se definió que los candidatos para cargos de elección popular tienen plenas facultades para gestionar o administrar sus cuentas en redes sociales sin que pueda darse injerencia alguna del Estado, en tanto ello forma parte de las libertades que el régimen democrático le concede a todo sujeto de derecho privado. (Voto 3252-E1-2018).

- Se indicó que quien, de forma voluntaria, decida participar de actividades que impliquen un alto grado de exposición pública, como una candidatura, debe someterse al escrutinio de la prensa y tolerar -hasta cierto grado- las declaraciones o informaciones que puedan perjudicarlo, pues tal exhibición conlleva la posibilidad de control por parte de la ciudadanía. (Voto 757-E12018)

- Se explicó que la restricción vigente para la difusión por cualquier medio de encuestas o sondeos de opinión elaborados por personas físicas o jurídicas no registradas ante el TSE, no resulta aplicable para el caso de sondeos privados de un grupo cerrado y específico de personas, quienes sí pueden compartir los resultados entre sí sin difundirlos fuera de ese conglomerado. (Voto 382-E8-2018).

- Se resolvió que, dado que existe una precisa distribución de funciones entre todos los agentes que participan del proceso electoral, los roles específicos 


\section{DERECHO ELECTORAL}

resultan ser exclusivos y excluyentes, por lo que no es posible que miembros de juntas electorales, por ejemplo, ejerzan labores propias de los fiscales o de los veedores, en tanto sus atribuciones y razón de ser dentro del engranaje de los comicios resultan ser específicos. (Voto 1039-E3-2018).

- Se dispuso que, ante la creación de un nuevo cantón, la administración de los intereses del nuevo municipio seguirá transitoriamente a cargo de la municipalidad de la que se segregó el territorio, por lo cual los miembros del concejo de distrito y el síndico del distrito, que se convirtió en cantón, continuarían desempeñando las mismas funciones asumidas conforme al mandato popular otorgado. (Voto 2645-E8-2018).

- Se reiteró que para poder reembolsar con la contribución del Estado los fondos erogados por los partidos, resulta indispensable que estos demuestren el gasto y que comprueben que el pago se hizo con fondos de la agrupación a través de uno de los medios admitidos, a saber, cheque, tarjeta de débito o transferencia. Ello operaría siempre y cuando resulte posible demostrar que el bien o servicio contratado fue pagado contra los fondos del partido, ya que, si se desea que un tercero realice la operación con sus propios fondos para que luego el partido reembolse los gastos, es necesario formalizar el respectivo contrato de intermediación en los términos del numeral 53 del Reglamento sobre el Financiamiento de los Partidos Políticos (RFPP). (Voto 4461-E10-2015).

- Se precisó que el monto definido como contribución del Estado a los partidos políticos en una elección particular no puede ser modificado por la Asamblea Legislativa, y que la ausencia de recursos suficientes para cumplir cabalmente con ese compromiso no extingue los derechos al aporte estatal adquiridos por las agrupaciones políticas y por los titulares de los certificados de cesión, por lo que estos podrían emprender acciones judiciales para reclamar esos derechos, lo que incluiría el pago no solo del monto dejado de percibir, sino también de las costas, daños y perjuicios causados. (Voto 7314-E8-2017).

- Se precisó que la adquisición realizada por un partido al vencimiento del término establecido en un contrato de arrendamiento con opción de compra supone una inversión y no un gasto, por lo que el pago del precio o su saldo pendiente no puede ser reembolsado con cargo a la contribución del Estado, salvo que se hubiese aplicado -total o parcialmente- en abono al precio lo pagado por alquiler, según lo pactado en el contrato. (Voto 5640-E8-2017).

- Se aclaró que en el tanto la contribución estatal se mantenga como reserva, no es susceptible de garantizar o responder por obligaciones -presentes o futurasde la agrupación política, por cuanto no constituye parte integral de su 


\section{DERECHOELECTORAL}

patrimonio, lo que le impide al partido disponer libremente de esos fondos. (Voto 7977-E3-2017).

- Se detalló que la figura del conflicto de intereses en las erogaciones efectuadas por los partidos políticos puede presentarse en el caso de que un proveedor de bienes o servicios de la agrupación figure, al mismo tiempo, como representante o agente de la agrupación. Se reiteró, en ese sentido, que de conformidad con la jurisprudencia electoral, el surgimiento de los conflictos de interés resulta ser motivo suficiente para proceder al rechazo de esos gastos. (Voto 1574-E1-2019).

- Se determinó que los miembros del comité ejecutivo superior de un partido pueden ser, a su vez, funcionarios y representantes del partido político, por lo que válidamente puede asignárseles un salario y gestionar su reembolso con la contribución del Estado siempre que sea la asamblea superior del partido político la que se encargue de definir el carácter remunerado de la función y el monto del salario correspondiente. (Voto 3197-E10-2019).

- Se estableció que el derecho de los partidos a liquidar gastos para recibir el reembolso con la contribución del Estado prescribe en diez años contados desde la última liquidación que hubiera presentado el respectivo partido político. (Voto 5686-E8-2020).

- Se reconoció que el contador público autorizado encargado de certificar la liquidación de gastos de un partido político en el trámite para obtener el reembolso de la contribución del Estado puede realizar su trabajo utilizando copias certificadas notarialmente de todas las facturas, contratos y demás documentos que respaldan los gastos. (Voto 6169-E3-2020).

- Se declaró que el TSE es el órgano jurisdiccional que deberá autorizar el levantamiento del secreto bancario y del secreto tributario que protege información confidencial de los contribuyentes partidarios, adquirentes de certificados de cesión o prestamistas, acreedores que omiten el cobro de sus acreencias, proveedores e intermediarios, ya sea de oficio $o$ a instancia de la Dirección General del Registro Electoral y de Financiamiento de Partidos Políticos o del Departamento de Financiamiento de Partidos Políticos, órganos que deberán requerirlo por solicitud debidamente motivada. (Voto 7285-E8-2015).

- Se indicó que el ordenamiento electoral permite las donaciones a partidos políticos a través de transferencias entre cuentas de un mismo banco o transferencias en la modalidad SINPE, pues lo que está prohibido es que quien figure como donante sea una persona jurídica nacional, o bien, una persona física o jurídica extranjera. (Voto 2378-E8-2019). 


\section{DERECHO ELECTORAL}

- Se tomó la decisión de establecer una sección especializada conformada por magistrados electorales suplentes, en la que se redimensiona dicha figura, para conocer, en primera instancia, de todos los asuntos contencioso-electorales que puedan culminar en una sanción, como lo son la destitución del cargo e inhabilitación para el ejercicio de puestos públicos (en el caso de las beligerancias políticas) o la supresión de la credencial (tratándose de los funcionarios de elección popular). Ello permite garantizar la posibilidad de presentar un recurso de reconsideración para reexaminar la cuestión a través de una instancia diferente (el pleno de magistrados propietarios) a la que dictó la primera sentencia. (Voto 3461-M-2017).

- Se precisó que la Inspección Electoral carece de competencia para instruir procesos de beligerancia política en contra de integrantes de los supremos poderes, pues en ese supuesto deberá actuar como órgano director un magistrado de la Sección Especializada. Sin embargo, se aclaró que cuando se interponga este tipo de denuncias contra ministros sin cartera, la Inspección Electoral será la instancia competente para actuar como órgano director, en tanto esas personas funcionarias no son miembros de un supremo poder, en el sentido estricto de la acepción. (Voto 4074-E8-2020).

- Se dispuso que los ciudadanos pueden prescindir de la exhibición de la cédula de identidad, en su formato físico, para acreditar su identidad cuando dicha identificación se realice mediante el "Servicio de Verificación de Identidad" (VID) que facilita el TSE. (Voto 2357-E8-2015).

\section{BALANCE final}

Después de analizar los aportes jurisprudenciales del TSE durante el período 20152020, queda claro que su intervención nunca lo fue para direccionar las preferencias del electorado, sino para hacer cumplir las reglas y condiciones de un entorno político electoral que promoviera la participación inclusiva de la ciudadanía y la vigencia del Estado democrático de derecho. Sin duda, dicha línea jurisprudencial contribuyó al cumplimiento de la agenda global que plantearon los ODS, en concreto el objetivo 5 referido a la igualdad de género, el objetivo 10 que propone la reducción de las desigualdades y las prácticas discriminatorias y el objetivo 16 que aboga por la paz, la justicia y la solidez de las instituciones y el Estado de derecho.

Resultados concretos como la promoción y tutela de la participación política en condiciones de igualdad, además de decisiones inclusivas que atendieron necesidades particulares de diversos segmentos de la población, logran vencer los obstáculos que dificultaban el ejercicio efectivo del sufragio activo y pasivo por parte de la ciudadanía. 


\section{DERECHOELECTORAL}

Asimismo, se fortaleció la democracia interna de los partidos en los procesos de selección de autoridades partidarias y de candidaturas a cargos de elección popular; y se analizó en profundidad la normativa establecida en la Constitución Política y en la legislación que limita en diversos grados la participación política de personas que ejercen función pública. Igual de relevante fue la delimitación de las obligaciones de imparcialidad en la función pública y la aplicación de sanciones por beligerancia política que evidenciaron la responsabilidad que corresponde a los servidores públicos en esta materia.

En otro orden de cosas, el desarrollo jurisprudencial de este período logró el establecimiento de garantías de seguridad jurídica para los actores del sistema político electoral. En este ámbito la intervención del TSE sirvió para establecer reglas claras y transparentes para ciudadanos, partidos políticos, candidatos y funcionarios públicos, es decir, para todos aquellos que tienen intervención activa o pasiva en el proceso.

Así, por ejemplo, se precisaron las competencias de la asamblea superior de los partidos y de las de menor rango, tanto en la definición de su estructura interna como en la designación de candidaturas. Se delimitó, también, la naturaleza y exclusividad de las funciones asignadas a otros órganos internos como el comité ejecutivo, la fiscalía, los tribunales de elecciones internas y los tribunales de ética y disciplina de las agrupaciones. Al mismo tiempo, se especificaron los derechos de sus militantes frente a las decisiones acordadas por dichos órganos y el alcance de las sanciones que pueden aplicarse dentro de estas organizaciones políticas.

Además, en otro ámbito de importancia, la línea resolutiva del TSE permitió garantizar que todos los ciudadanos tuvieran acceso, en condiciones de igualdad, a fuentes de información que les permitieran tomar decisiones en el ejercicio de su ciudadanía activa. También fueron relevantes las determinaciones referidas a la utlización responsable de los medios digitales en la actividad político electoral y el fortalecimiento del proceso de deliberación informada en el contexto de las campañas políticas.

De lo dicho se puede concluir que las decisiones adoptadas por el TSE durante el período 2015-2020 contribuyeron al establecimiento de un entorno estable con reglas claras para la competencia electoral y garantías para todos los participantes en el proceso. Se evidencia, así, la construcción de un ambiente político electoral idóneo para la participación en condiciones de libertad y seguridad jurídica, lo cual abona al cumplimiento de los ODS en esta materia. Es decir, a partir del trabajo realizado, las ciudadanas y los ciudadanos contaron con herramientas suficientes para participar activamente en las decisiones políticas que les conciernen, para hacerlo en un entorno de reglas claras y de plena seguridad jurídica, para conocer, contrastar y discernir 


\section{DERECHO EIECTORAL}

entre las opciones que participaron en la contienda y para prevenir transgresiones y asegurar la vigencia plena de sus derechos y libertades político-electorales.

\section{REFERENCIAS BIBLIOGRÁFICAS}

Barrero, D. y Barquero, F. (Ene.-Mar., 2020). Objetivos de Desarrollo Sostenible: un contrato social posmoderno para la justicia, el desarrollo y la seguridad. Revista Científica General José María Córdova, 18(29), 113-137.

Binder, A. (2001). Entre la democracia y la exclusión: la lucha por la legalidad en una sociedad desigual. Buenos Aires: Ediciones del INECIP.

Dahl, R. (1999). La democracia: una guía para los ciudadanos. Madrid: Editorial Taurus.

Fernández, J. (2018). ODS 16: paz, justicia e instituciones fuertes. Recuperado de http://www.ieee.es/Galerias/fichero/docs_investig/2018/DIEEEINV18-20180DS.pdf

Freidenberg F. y Saavedra, A. (Jul.-Dic., 2020). La democracia en América Latina. Revista Derecho Electoral, (30), 1-42. Recuperado de: art/30/freidenberg_saavedra.pdf https://doi.org/10.35242/RDE_2020_30_1

Santamaría, J. (1987). Apuntes de Derecho Administrativo: el personal al servicio de la administración pública. Madrid: Editorial de la Universidad Complutense de Madrid.

Organización de Naciones Unidas (ONU) (2020). Objetivos de desarrollo sostenible. Recuperado de https://www.un.org/sustainabledevelopment/es/gender-equality/

\section{JURISPRUDENCIA}

Todos los votos referenciados pueden ser consultados en el siguiente enlace https://www.tse.go.cr/jurisprudencia.htm 